\title{
An Interpretative Phenomenological Analysis of Posttraumatic Growth in Adults Bereaved by Suicide
}

\author{
ANGELA SMITH \\ Institute of Work, Health, and Organisations, University of Nottingham, \\ Nottingham, England \\ STEPHEN JOSEPH \\ School of Sociology and Social Policy, University of Nottingham, England \\ ROSHAN DAS NAIR \\ Institute of Work, Health and Organisations, University of Nottingham, England
}

\begin{abstract}
This study explored experiences ofposttraumatic growth in adults bereaved by suicide. Six participants were interviewed using a semi-structured interview schedule. Transcribed interviews were analyzed from an interpretative phenomenological framework. Two superordinate themes, with three ordinate themes in each, were identified: (a) positive growth ("life view," "knowledge of self," and "relation to others") and (b) social context ("gaze of others," "public guise," and "solace of other survivors"). Suicide survivors gain extra insights due to their experiences, but are reluctant to acknowledge that they do. This requires consideration in theoretical and clinical settings.
\end{abstract}

Posttraumatic growth (PTG) is the term used to describe the heightened levels of personal development that can be achieved after trauma (Linley \& Joseph, 2004). While the majority of research into PTG has investigated survivors of illness, accidents, and disaster, a small body of research has developed into bereavement as a trigger to PTG (e.g., Davis,

Received 27 November 2009; accepted 25 August 2010.

Address correspondence to Angela Smith, Institute of Work, Health and Organisations, International House, Jubilee Campus, University of Nottingham, Nottingham NG8 1BB, United Kingdom. E-mail: 1wxams@ nottingham.ac.uk 
Nolen-Hoeksema, \& Larson, 1998; Parappully et al., 2002; Park \& Cohen, 1993; for a review, see Schaefer \& Moos, 2001; Yalom \& Lieberman, 1991). No research has yet examined the lived experiences of PTG in bereavement by suicide.

In 2006, 5,554 adults (aged 15 years or above) took their own life in the UK (Office for National Statistics, 2008). It has been suggested that for every person who dies by suicide there are at least six people significantly affected by that death (e.g., Pompili et al., 2008). McGlothlin (2006) reported that 4.5 million people worldwide are impacted by the suicide of a loved one each year, leading to complex grief responses (McMenamy, Jordan, \& Mitchell, 2008; Melhem et al., 2004), prolonged depression, posttraumatic stress symptoms (Melhem et al., 2004), poorer physical health (Shepherd \& Barraclough, 1974), stigma (Cvinar, 2005), guilt and blame (Van Dongen, 1993; Silverman, Range, \& Overholser, 1995), and an increased risk of their own suicidal intent (Andriessen, 2005; Callahan, 1996) or completed suicide (Calhoun, Selby, \& Selby, 1982; Melhem et al., 2004; Pompili et al., 2008).

In light of this research, it would be less expected for PTG to arise in bereavement from suicide compared to other traumatic experiences. However, a recent study asserted that personal growth represents an important part of healing in parents who have lost a child to suicide (Feigelmen, Jordan, \& Gorman, 2009). But as this was a large-scale questionnaire-based study, it was not able to explore in depth what actually constituted growth for people bereaved by suicide. Therefore, further qualitative explorations of the idiographic understanding of PTG are required. Indeed, a literature review indicated that few papers tell the story of people's experiences beyond the suicide (Maple, 2005). Begley and Quayle's (2007) qualitative investigation of the lived experience of people bereaved by suicide revealed "purposeful-ness"as a master theme. Purposefulness refers to the determination to find meaning in life after a loss. The authors highlighted the need to further understand meaning-making processes to gain deeper insights into the distinctive nature of bereavement by suicide. This study explored the general experience since the suicide, rather than growth specifically. The study aims to further our knowledge of PTG in adults bereaved by suicide by examining their lived experience of growth since their bereavement.

\section{METHOD}

Interpretative phenomenological analysis (IPA; Smith, 1996a, 1996b) was used to explore the meaning of the experience for each individual, rather than generate general theory. IPA permits researchers to interpret, based on their own experiences and knowledge, the participants' accounts. A flexible IPA framework guided the analysis (Harding \& Gantley, 1998; Smith \& Osborne, 2003). 
Sample

A purposive, self-selected sample of six participants took part in the study. Participants responded to information disseminated by charity organizers, and snowball sampling was conducted through Samaritans (a charity providing a listening service to people experiencing distress and despair, including thoughts of suicide) and Survivors of Bereavement by Suicide (a charity established to support bereaved people by other survivors of suicide bereavement).

To be included in the study, participants were required to (a) have been bereaved by suicide more than 2 years prior to participating in the study, (b) speak English, and (c) be 18 years of age or older. People with either an uncorrected hearing impairment or a disability resulting in an inability to verbally complete the interview and those unable to provide informed consent were excluded from participation.

\section{Data Collection}

The lead researcher conducted and digitally recorded six semi-structured interviews, ranging from 50 minutes to 2.5 hours. The recorded interviews were transcribed verbatim. All six interviews were conducted at participants' homes. Participants were requested to describe their experience, in particular their perception of life since their loss. A semistructured interview permitted questions as a prompt, alongside the flexibility for the researcher to adapt to the participant's account. The purpose of the interview as described to the participants was to discuss ways they felt life may have changed or remained the same for them since their loss.

The semistructured interviews were designed to be free of double negatives or technical jargon and leading content or assumptions, and questions were piloted with colleagues. The interview schedule used the following questions/prompts:

- Tell me about your experience of losing someone to suicide.

. How has life been since your loss?

- What does that change mean for you?/What does it mean to you that it remained the same?

What else might you want to tell me that we have not included?

Neutral questions were selected to allow participants the freedom to respond with narratives that may confirm or deny growth, allowing data to emerge from the respondents' discourse spontaneously. The questions also permitted responses that might illustrate how growth had come about for individuals.

Incidentally, the interview schedule was rarely utilized; instead the researcher relied on clarifying the meaning derived by individuals of a topic described (e.g., "What did that mean for you?"“"How did you experience 
that?"“What was that like for you?") and reflecting/summarizing points to prompt further description. All participants were made aware of the lead researcher's personal history prior to the interview and informed that they would be given space to discuss these accounts after the interview so as not to influence their individual accounts. Participants were contacted approximately 1 week after the interview via telephone to discuss any ensuing concerns.

\section{Analysis}

Each interview transcript was read and reread initially, noting summative descriptions of the participant's account in the left margin and interpretative statements in the right margin. A process of collating interpretative statements into groups was completed once transcripts had been thoroughly read. Connections between groups were identified to provide themes. Lists of themes were developed into a diagram created for each interview. All themes were combined as the analysis progressed. Circularity of interpretation meant that newly emerging themes were explored in previously analyzed transcripts to inform the final research themes. Themes not integral to the aim of the study were also identified though not reported in this article.

No preset criteria by which to evaluate whether positive growth had occurred were employed given the idiosyncratic nature of each participant's development. Participants were informed about the nature of the study, and the interview structure allowed them freedom to discuss areas in which they perceived themselves to have "grown."The interpretative nature of the IPA framework allowed the researchers to make inferences about where they felt a person may have changed based on the content of each person's narrative.

\section{Quality Assurance Measures}

The phenomenology within the study comes from the participant. However, due to the double hermeneutic employed as a central tool in IPA, the researchers' interpretation of the narrative and thus the "growth"is interpreted by the researchers. Thus, "member checks"that might be used in other qualitative approaches were not employed in this study, as this would provide additional hermeneutic stances. Indeed, a participant's own account may have changed with each "check"due to time passing.

Faithful to the aims of qualitative inquiry, the researchers sought to assure quality by establishing the trustworthiness of the findings (Lincoln \& Guda, 1985). This is particularly important in IPA research, which relies heavily on the researcher's interpretation. Trustworthiness was established by the following means: An audit trail of analytical processes was maintained to generate a transparent and explicit decision-making process (Biggerstaff \& Thompson, 2008) permitting themes to be traced back to statements made 
by participants in their interviews, and quotations provided from participants' accounts ensure that the reader can assess the credibility (Beck, 1993) of themes. Additionally, a reflective diary that commenced prior to the interviews being conducted and continued until the completion of the analysis was kept so that data could be repeatedly scrutinized by the researchers to ensure that there was not an inequitable emphasis on individual themes. The lead researcher derived the main themes; however, discussion with the coauthors served as a means to ensure that the interpretations accurately reflected, without over- or under-representation of elements of, the raw data.

To contribute toward the transparency of the study, it is important that the reader understand the background of the lead researcher so to have an understanding of the influences on the interpretation of transcripts. The lead researcher had previous experience of bereavement by suicide; her father died 12 years and her brother 2.5 years prior to the study commencing. The reflective diary was utilized to document the potential influence of the lead researcher's previous personal history, given concerns about extrapolating data that were not present in participants' accounts but purely based on the lead researcher's experience. Moreover, during the analysis stage reluctance was noted in permitting themes to emerge due to the fear of merely replicating previous studies. The same researcher conducted all interviews.

\section{RESULTS}

\section{Sample Characteristics}

The final purposive sample comprised six participants (three male, three female). One participant had been bereaved by suicide twice. Participants' ages ranged from 40-72 years. Table 1 outlines the relationship between the deceased and the bereaved and the length of time since bereavement.

\section{Overview of Themes}

IPA yielded process of time as an overarching transcendence to thematic contextualization, a ubiquitous thread in all themes. This theme does not suggest

TABLE 1 Participants' Relationship to the Deceased and Time Since the Suicide.

\begin{tabular}{llc}
\hline Participant pseudonym & Person lost & Time since death (years) \\
\hline Stephen & Wife & 12 \\
Belinda & Close friend & 2 \\
Roger & Daughter & 15 \\
Lorna & Son & 10 \\
John & Sister & 19 \\
Tracey & Son & 3 \\
& Brother & 33 \\
\hline
\end{tabular}


it is possible to give a time frame by which people might judge when growth may begin. The theme instead serves to highlight that the bereavement process and any subsequent growth are not necessarily divisible into stages and seemed to be dynamic in nature. There was a sense from participants that they had moved from one state of being into another and back, and some areas of PTG had gained more and less prominence for people over time. For example, according to Roger (all names are pseudonyms): "I wouldn't

talk likethis ifIwere6 monthsinto the bereavement'? Thethemesthatwereextrapolatedfrom the datacomoboratedthe "stages" of bereavement detailed in previous literature (such as Ku"bler-Ross, 1969). As these are well documented elsewhere, they are not outlined here. Themes developed in this study were not discrete; each was complex and contained a number of convolutions.

Posttraumatic growth was identified as a superordinate theme within which three overlapping ordinate themes were derived: "life view,"“"knowl-edge of self," and "relation to others."

\section{Positive Growth}

Interpretation generated elements that had changed for participants, for the better, as a result of their loss. These elements were broadly encapsulated under the ordinate theme titles outlined below.

\section{LFEVIEW}

Participants were understood as having developed greater awareness of certain aspects of life and their place in the world. The experiences heightened their awareness of their existence in the world; they started to consider their relation to the world and life surrounding them. There was a sense of understanding what it meant to be alive.

Dead means dead. And because you're on this planet you're alive. [There is] an assumption that you [are] actually really living if you are existing on this planet. (Roger)

There appeared to be a reciprocal relationship between participants having a greater awareness of their existence and consideration of their own mortality. The suicide of their loved one had forced people to confront why someone would want to die and what mortality means to them.

To me immortality is how people remember you. ... I don't believe in life after death in the solid sense of it but. . . immortality I think it's ... . how you're remembered by people. I mean obviously that's a, that's not a finite thing is it, it's a time limited thing. ... My immortality to me will be how my 
boys remember me and how my grandchildren, and if they talk, and if they

talk about. . . me to their daughter or son, or whatever. (Belinda)

Awareness of mortality alongside consideration of the reasons for their loved one ending their life prematurely was not necessarily growth itself; rather, it was interpreted that the effects of having this awareness led to a desire to get the most from life, and so participants appeared to seize opportunities as they were presented.

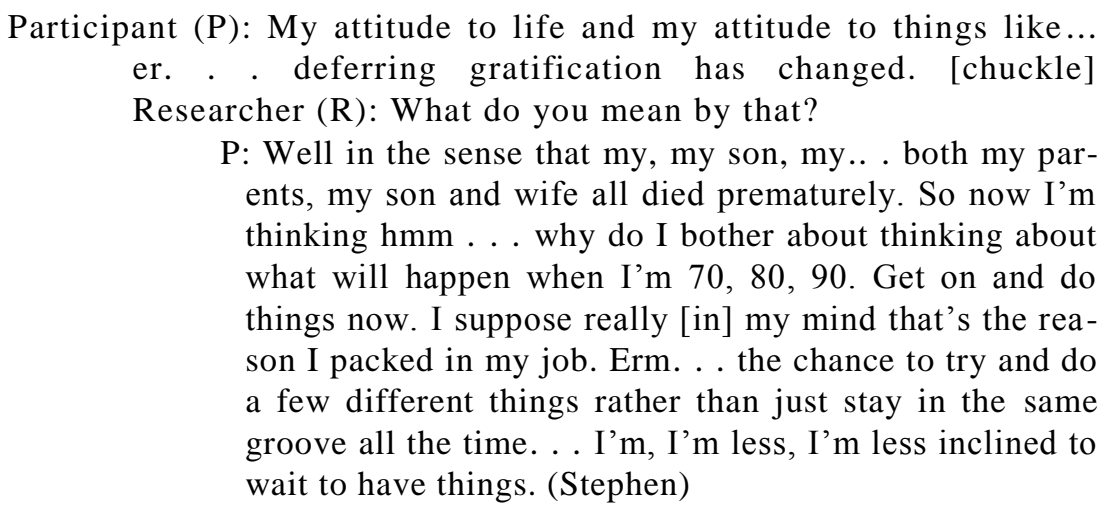

The desire to take every enjoyment from life is not necessarily with disregard for other aspects of life; indeed, participants reported it serves the purpose of distracting from the underlying pain of having lost someone to suicide, which has the incidental effect of providing a greater sense of freedom.

I'm never going to change what's happened, and it's a fact that I've got to make the best of what I've got left of my life, so I no longer plan what I'm going to do. I try and live every day how I can, and I try and do as many things that are uplifting and that are going to make me feel better. (Tracey)

Participants discussed the idea of life's unpredictability. Their existence not being within their control was deduced to heighten the sense of needing to get as much as they can from their life while they can.

We like to think of ourselves as being in control of our lives and think we're a lot less in control than we like to admit. . . our lives are basically a sequence of accidents and coincidences. (Stephen)

\section{KNOWLEDGEOFSELF}

Participants discussed their individual relationship with the deceased, but invariably discussed how that role was in some way distinct from their self in existence. In seeing these as distinct, participants were construed as having a greater sense of the core self. 
I'd geared a lot of what I was doing to supporting my wife...and now I didn't have to do that. And it was a very strange sensation thinking well actually I can now do, well. . . within reason I can do exactly as I please. (Stephen)

Participants were considered to have a greater awareness of who they were, independent of other duties and roles, meaning mistakes in one role in life did not necessarily impact on one's sense of self.

I feel as though, as a person I felt justified in saying it. Her father, as her father I wish that I'd had more patience, more understanding, more love. (Roger)

Participants stated they were more aware of their psychological capabilities, what they were able to do and what might be too much for them. Metaphors were often used to describe this idea, such as a boat with "witting and unwitting cargo"referring to things voluntarily loaded onto the ship by an individual versus things loaded against one's better judgment and choice, usually as a result of life's unpredictability.

Well to me that sums up life, everybody's doing it, whether they're aware they're balanced, or, or by doing a balancing act or not. When I was young. . . a young married man with small children, it was more like that. . . keeping about half a dozen balls in the air. . . doesn't perturb me anyway to say that my life is on a fine balance because I am aware that it's a very fine balance. As long as I keep the awareness I think. (Roger)

Psychological growth does not dictate that a person is able to cope with more emotional strain; indeed, it could be less since the bereavement. The growth, per se, was the recognition of what will lead to strain and an increased willingness to attempt to control the amount they take on.

Before I would take on lots of things and erm, and feel guilty if I ever kind of said no to people. Whereas now I think, no, I've got to sort of be careful.. . I kind of don't do that now because I think it is better to do things properly but slowly and just take my time because I haven't got the same sort of capacity as I had before, really, to sort of take on tasks, really, as it were. (Tracey)

It was extrapolated that coping strategies were developed or strengthened as a means of ensuring that each person's psychological capabilities were not overstretched, negating the impact of upsetting incidents and increasing a person's governance of his or her emotions. These coping strategies took on many forms. Explicitly, people discussed: purposefully avoiding certain events or places, particularly around the time of the anniversary of the person's death; mentally preparing for future events; or distracting themselves with activities. 
P: I remember taking, taking myself off to the pub. . with a book. ... I remember just sitting sort of, in a corner with a book. It was somewhere to go where there was some noise; there were other people in the place.

$\mathrm{R}$ : What do you think it is about the noise?

P: I. . . I think it's, I think it's a distraction as much as anything else. It's something you can pay attention to. (Stephen)

Unspoken means of coping were also used within the interviews, which was interpreted as a means to distract the interviewer away from painful subjects and impeding emotional disclosure while the participant was in the presence of an "other."Such means included use of humor, diverting to an alternative perspective (such as use of the collective term "we"or from the perspective of the deceased), use of third person references to oneself, or use of physical restraints to prevent oneself from revealing emotions such as a controlled cough. Stephen provides an example of humor: "How am I dealing, how is my grieving? Telephone

08457 [laughter].'In addition, the following is an example of diverting to an alternative perspective:

R: What were they like for you?

P: I think she'd've laughed at us having a memorial service (Belinda)

Through the use of explicit and implicit coping strategies, participants were taken to have increased control over their emotions at any given point, which was acknowledged by some. However, participants acknowledged times when they might be "caught off guard"or unexpectedly feel low. Yet, it was inferred that, as time passes, there is an ability to allow themselves to experience low moods without necessarily actively struggling against the feeling, trying to continue to function regardless of the low mood, berating themselves for being "weak,"or indeed worrying the feeling will get worse. Their increased emotional governance afforded a leniency for temporary low moods, as there was knowledge the low period will end. Indeed, perhaps allowing low moods, within reason, was necessary to permit ongoing emotional governance the remainder of the time.

$\mathrm{R}$ : Those times when you have been caught, what are they like for you?

P: I don't worry about it because I know it won't last very long. You know, I've found this, it will just pass of its own accord. (Stephen)

The explicit recognition of a coping strategy and its active implementation to mitigate a low mood may provide individuals with greater 
governance over their emotional state. We would caution, however, that active coping per se is not necessarily indicative of growth, although it is likely that active coping strategies provide the vehicle for growth.

\section{RELATIONTOOTHERS}

Some participants reported they either noticed more about the emotional states of others or perhaps were more willing to ask questions to find about others' feelings.

It was just something I didn't really think about, you know again I, it was the classic. . . oh how are you, alright? Yeah fine. . . an, or the classic are, are, are you OK? And actually as you are walking off and not waiting for the answer, you know. And I don't do that anymore but erm . . . I'm I think better at spotting people who aren't in a good place. (Stephen)

Participants appeared to be less likely to assume things about others, realizing the idiosyncratic nature of each person's life.

I think that you should never judge a situation from how you first see it, because there's often a lot more in the background than you ever imagine. (Tracey)

There was consensus that people were less willing to risk upsetting others. This may have involved not wanting to get into arguments, not showing one's own upset to avoid upsetting others (see public guise), or just a consideration of other people's life events so one's actions might not be considered "thoughtless."

So one of the things that's come out of this for me is that I am very careful about my choice of Christmas cards and who I send what to. I now think very hard about whether they've had any sadness in their particular life that year or you know whatever and send an appropriate card because to me it was just unbelievable that somebody just knowing, full knowing that we'd lost our son, just picked the next card out of the box without even so much as a cursory glance at it. (Lorna)

Beyond merely ensuring they did not upset others, all participants were construed as going "out of their way"to meaningfully contribute toward the lives of others. They appeared to demonstrate enhanced munificence, a desire to give to others either ad hoc or through purposeful actions such as voluntary work. Some participants reported what they considered to be altruistic acts of practical and emotional munificence. This could involve " giving back"to those who helped them and passing on their experiences to other survivors. This was perhaps indicated simply by participants' desire to contribute to research such as this. 
It's difficult to see any positive elements that [come] out of suicide but the one is that you can help other people who are so traumatized after the death. (Tracey)

As an extension of the sensitivity in noticing when others are low, participants were viewed as more likely to extend a supportive hand to others, even strangers, than prior to their bereavement. For example, according to

\section{John: 'T'vegot tolook after peoplemore.'Duningtheanalysis stageand thecollation of statements intogroups, we} became aware of the ways in which the participants had talked about their experiences in relation to how they were viewed by others and the perceived appropriateness of discussing positive changes. This led us to reflect on whether we had inadvertently presented participants' experiences of growth as a purely cognitive process. As such, we revisited our data in order to examine the social aspects of growth. A second superordinate theme of "social context"emerged with three ordinate themes: "gaze of others,"“"public guise,"and "solace of other surviv" ors."

\section{Social Context}

The second superordinate theme of social context was not concerned with added personality characteristics or growth, but instead highlights the social context within which growth takes place; this is fundamentally involved in all areas of positive growth. Participants' accounts were interpreted as concerned with how they appeared to others and what others might think of them. The "other"was broadly divided into the general other and other survivors of bereavement by suicide.

\section{GAZEOFOTHERS}

Gaze of others refers to the inescapable element of the participants' accounts referring to how they believed themselves to be viewed by other people.

Thinking what people think of you. Erm ... . oh you know, people say they don't, they don't really care what people think about them, I mean I've said it myself, but there are things that you do care about, aren't there? (Belinda)

The gaze of others may leave them feeling they were locked into a certain role, differing from their own view of the self.

I suppose that we will always be known by the people around here, you know the couple who. . . lost a son. . . to suicide. I can't do anything about that, I try not to think about it. (Lorna)

Participants considered how disclosing their innermost emotions in public would affect people's view of them: Some feared exploitation by others if they exposed any form of weakness, whereas others did not want 
to appear incompetent in the role the "other"knew them in; still other participants worried about the embarrassment of showing upset.

A show of emotion is a weakness.... I would like to be close enough to somebody whereby I could actually do that. (John)

\section{PUBLICGUISE}

Participants described having a public presence, which masked their underlying emotions and was construed to serve the purpose of deflecting the gaze of others, saving participants from emotional disclosure. The public guise appears to give others the impression of the bereaved being at least "functional"and at most "over it."This public guise was believed to be easier to maintain once a person has increased the knowledge of the self, allowing a sense of emotional governance maintained by coping strategies.

I always put on a very good act, so that people imagine that I'm actually doing very well. You know, people will say, "Oh god, that Tracey, she's,

youknow, it'samaring Lookather,she'sdoingthis, that, and theother.'Buttheyactuallydon'tknowwhat'sinmyhead andIthinkiftheydidtheywouldbeverysuppised(Tracey)

Public guise was not interpreted as a void of emotions, but merely as emotions that are disguised and hidden from others.

I'm far too much in control of my own emotions. I'm certainly very good at controlling my emotions.... And no I don't show it, and yes I'm in complete control. But privately. (John)

It was felt that the public guise allowed participants to choose when and to whom they reveal their underlying feelings, providing them with protection against revealing their emotions unwillingly.

I've never been in a situation where I've been close enough to a person to allow myself to open up to an extent whereby I would not think that they were then going to use that against me. (John)

The public guise was interpreted to not only protect the participants, but also was seen as a munificent act. In considering others and not wanting to risk upsetting them, the public guise acted as protection for others from the participant's true emotional state.

I suppose that's all bubbling away, and you feel that, it's a lot of that is under the surface sometimes, but you can't actually say anything to other people, because you don't want to shock other people, you don't want to upset other people, and you don't want to certainly lower the tone, 
because people like to hear about uplifting things. They don't want to hear about anything downbeat or depressing. (Tracey)

\section{SOLACEOFOTHERSURVIVORS}

The feeling of social perception was considered as different for the participants when among other survivors of bereavement by suicide. On the whole, participants seemed to find relief from the gaze of others and were able to drop their public guise when they were with other survivors. Participants regaled the benefits of contact with other survivors.

I found that a big help to me to be able to talk to others and exchange views, opinions, suggestions, you know, experiences in general to do with suicide bereavement. (Lorna)

Even years after their bereavement, participants felt only others bereaved by suicide understood their experience, and it influenced their ability to speak to people about the death. Even though the interview for this study was designed for people to be open, participants felt that speaking to someone they knew was also bereaved by suicide made the exchange easier.

See, if you weren't bereaved, I wouldn't really want to talk to you. . . . I know that you know what I, where I'm coming from. But if it was somebody else, I just wouldn't, I wouldn't talk to them in that same way, because you've got a different level of understanding. (Tracey)

However, even within the solace of other survivors, it appeared that the idea of growth remained unmentionable. Some participants were able to explicitly discuss ways in which they had grown with the researcher during the interview, perhaps as a result of the nature of the study, but said that they felt unable to do so when with other people, even other survivors.

Can good things come out of suicide?. . Yes they can. Do we want to talk about them? Do we want to say I feel better because of this, they say, "no, don't put your mouth on it!"That's what I think. But nevertheless, good things $d o$ come out of it . . . for a price. (Roger)

Some participants explicitly acknowledged that some of the outcomes from their experience were positive, though acknowledgment of these elements of growth was difficult given the source of the positive outcomes.

I think that some good things have come out of the terrible loss that we had, but other people might not consider them to be. . . that I don't know. (Lorna)

Having said that I'm still not sure that the silver lining's worth the cloud. (Stephen) 


\section{DISCUSSION}

This study has presented a detailed exploration of six participants' experiences of bereavement by suicide, with specific attention given to areas of PTG. The theme of positive growth and its subthemes closely replicate the findings of growth after other traumatic events (Linley \& Joseph, 2004), illustrating that the concept of positive growth can be applied to bereavement by suicide. However, the second theme of social context is a facet that has not previously been discussed in studies regarding growth after other traumas. Social context, and its implication for growth experiences, appears to be a distinctive feature of bereavement by suicide. Given the theme of social context and its influence on the lack of acknowledgment of growth after bereavement by suicide, it is perhaps pertinent to consider fully the implications in applying growth-oriented interventions.

The study indicated that participants had a greater understanding of their existence; altered their actions in order to truly live while alive; had an ability to govern their emotions, permitting low moods when they occurred; employed coping strategies to mitigate their low moods; and thus maintained a public guise. The desire to gain meaning in life and understand their own existence could be considered akin to Begley and Quayle's (2007) theme of “purposefulness."Analyses demonstrated an alteration in their relation to others through sensitivity to feelings and increased munificence. The findings support previous assertions that PTG is experienced by those bereaved by suicide (Feigelmen et al., 2009) and further our understanding of the idiosyncratic nature of growth situated within the context of social perception, which means growth after suicide bereavement may be more difficult to discuss than growth after other traumas, with that growth possibly being deemed more socially acceptable.

It may appear that the results indicating positive growth are incongruent with past research (detailed earlier) revealing negative outcomes for those bereaved by suicide. However, it is important to note that the presence of growth for some participants does not denote the absence of distress. Instead, the results highlight some areas of positive change that can go alongside distress.

PTG is not yet a prominent feature of the suicide literature, despite it being evidenced in bereavement of other forms. Perhaps this is partly due to the social context, and in turn its absence from the literature serves to maintain these social perceptions. Thus, there are implications for bereavement theory and consequently bereavement support, particularly in work with those bereaved by suicide.

\section{IMPLICATIONS}

The concept of "growth"needs to be normalized among the grieving so that people can discuss the ways they feel they have changed and developed 
without fear of judgment. It is commonly accepted that people dealing with a problem must first admit they have a problem; likewise, the initial step in fostering growth is to acknowledge its possibility.

Bereavement counseling currently focuses on giving people space to explore their loss and the impact it has on their life and to "identify and resolve the conflicts of separation"(Worden, 2001, p. 101), as well as on the normalization of the bereaved person's emotional experience. In the case of traumatic loss, where necessary, consideration is also given to the acceptance of not ever being able to know all of the facts surrounding the loss (Cruse Bereavement Care, 2006). It is a skill of the bereavement counselor or therapist to hold in mind that bereaved people are regularly able to regain function in life despite their perhaps feeling they will never function properly again. We speculate that growth might be a natural extension of the grieving process, beyond the end point of "acceptance"(Ku"bler-Ross, 1969). As such, it is important to provide the bereaved with the opportunity to explore the possibility of gaining through their adversity. However, professionals should be cautious not to imply that growth is expected or is necessary.

\section{Limitations}

IPA assumes that all individuals have the ability to articulate their thoughts (Smith, 1996b). However, our participants used different means to communicate their experiences, including nonverbal cues, metaphors, diagrams, and emotive language, which are accepted generally as appropriate means of communication (Wilbram, Kellet, \& Beail, 2008). Therefore, given the verbal load of IPA, some of these more subtle forms of communication may have been missed in our analyses. Purposive sampling was employed to ensure that people bereaved by suicide participated; however, it is acknowledged that people who volunteered were motivated by emotional drives to help others understand the experience and are able to discuss their experience. Growth may be an anomalous facet present in this sample, perhaps unrepresentative of survivors in general. However, representativeness was not the objective of this study, nor is it the objective of many qualitative studies, which emphasize an ideographic approach to knowledge production and comprehension. There is a need to address the ability to access the emotionally vulnerable population in a nonthreatening manner to include people who may feel unwilling to volunteer for participation.

The lead researcher's personal experience may have reduced the objectivity during the analysis, but in adopting a double hermeneutic stance objectivity was not sought. The researcher could be considered to provide "theoretical sensitivity"(Glaser, 1978). The detailed reflective diary and audit trail were used to ensure that the researcher's own experiences did not gratuitously emphasize themes. Additionally, one participant was "on record"as 
saying that the researcher's prior experiences made it easier to be open; this was corroborated informally by three other participants.

Future Research

Investigation into the clinical applications of this research is called for. Research is needed to examine each of the themes in more depth. In particular, the novel theme of social context is worthy of study because of the possibility to extrapolate means of altering the social dialogue with regard to suicide bereavement.

\section{REFERENCES}

Andriessen, K. (2005). A reflection on "suicide survivor."Crisis, 26, 38-39.

Beck, C. T. (1993). Qualitative research: The evaluation of its credibility, fittingness and auditability. Western Journal of Nursing Research, 15, 263-266.

Begley, M., \& Quayle, E. (2007). The lived experience of adults bereaved by suicide: A phenomenological study. Crisis, 28, 26-34.

Biggerstaff, D., \& Thompson, A. R. (2008). Interpretative phenomenological analysis: A qualitative methodology of choice in healthcare research. Qualitative Research in Psychology, 5, 214-224.

Calhoun, L. G., Selby, J. W., \& Selby, L. E. (1982). The psychological aftermath of suicide: An analysis of current evidence. Clinical Psychology Review, 2, 409420.

Callahan, J. (1996). Negative effects of a school suicide intervention program-A case example. Crisis, 17, 108-115.

Cruse Bereavement Care. (2006). For people affected by natural disasters, terrorist attacks, and other traumatic losses. Retrieved from http://www.bereavementcare.org.uk/pdf/TraumaticLossCMP.pdf

Cvinar, J. G. (2005). Do suicide survivors suffer social stigma?: A review of the literature. Perspectives in Psychiatric Care, 41, 14-20.

Davis, C. G., Nolen-Hoeksema, S., \& Larson, J. (1998). Making sense of loss and benefiting from the experience: Two construals of meaning. Journal of Personality and Social Psychology, 75, 561-574.

Feigelmen, W., Jordan, J., \& Gorman, B. S. (2009). Personal growth after a suicide loss: Cross-sectional findings suggest growth after loss may be associated with better mental health among survivors. Omega, 59, 181-202.

Glaser, B. G. (1978). Theoretical sensitivity. Mill Valley, CA: Sociology Press.

Grad, O., \& Zavasnik, A. (2002). Shame-The unbearable legacy of suicide. In D. De Leo, A. Schmidtke, \& R. F. W. Diekstra (Eds.), Suicide prevention: A holistic approach (pp. 163-166). Amsterdam, the Netherlands: Kluwer Academic.

Harding, G., \& Gantley, M. (1998). Qualitative methods: Beyond the cookbook. Family Practice, 15, 76-79.

Ku"bler-Ross, E. (1969). On death and dying. New York, NY: Macmillan.

Lincoln, Y. S., \& Guda, E. G. (1985). Naturalistic inquiry. Newbury Park, CA: Sage. 
Linley, P. A., \& Joseph, S. (2004). Positive change following trauma and adversity: A review. Journal of Traumatic Stress, 17, 11-21.

Maple, M. (2005). Parental bereavement and youth suicide: An assessment of the literature. Australian Social Work, 58, 179-187.

McGlothlin, J. M. (2006). Assessing perturbation and suicide in families. The Family Journal: Counseling and Therapy for Couples and Families, 14, 129-134.

McMenamy, J. M., Jordan, J. R., \& Mitchell, A. M. (2008). What do suicide survivors tell us they need? Results of a pilot study. Suicide and Life-threatening Behaviour, 38, 375-389.

Melhem, N. M., Day, N., Shear, K. M., Day, R., Reynolds, C. F., \& Brent, D. (2004). Traumatic grief among adolescents exposed to a peer's suicide. American Journal of Psychiatry, 161, 1411-1415.

Office for National Statistics. (2008). Suicides: Small decrease in 2009. Retrieved from http://www.statistics.gov.uk/cci/nugget.asp?id=1092

Parappully, J., Rosenbaum, R., van den Daele, L., \& Nzewi, E. (2002). Thriving after trauma: The experience of parents of murdered children. Journal ofHumanistic Psychology, 42, 33-70.

Park, C. L., \& Cohen, L. H. (1993). Religious and non-religious coping with the death of a friend. Cognitive Therapy and Research, 17, 561-577.

Pompili, M., Lester, D., De Pisa, E., Del Casale, A., Tatarelli, R., \& Girardi, P. (2008). Surviving the suicides of significant others: A case study. Crisis, 29, 45-48.

Schaefer, J. A., \& Moos, R. H. (2001). Bereavement experiences and personal growth. In M. S. Stroebe, R. O. Hansson, W. Stroebe, \& H. Schut (Eds.), Handbook of bereavement research: Consequences, coping and care (pp. 145-167). Washington, DC: American Psychological Association.

Shepherd, T. L., \& Barraclough, B. M. (1974). The aftermath of suicide. British Medical Journal, 2, 600-603.

Silverman, E., Range, L., \& Overholser, J. (1995). Bereavement from suicide as compared to other forms of bereavement. Journal of Death and Dying, 30, 4151.

Smith, J. A. (1996a). Beyond the divide between cognition and discourse: Using interpretative phenomenological analysis in health psychology. Psychology and Health, 11, 261-271.

Smith, J. A. (1996b). Qualitative methodology: Analyzing participants' perspectives. Current Opinion in Psychiatry, 9, 417-421.

Smith, J. A., \& Osborne, M. (2003). Interpretative phenomenological analysis. In J. A. Smith (Ed.), Qualitative psychology: A practical guide to research methods. London: Sage.

Van Dongen, C. J. (1993). Agonizing questioning: Experiences of survivors of suicide victims. Nursing Research, 39, 125-141.

Wilbram, M., Kellet, S., \& Beail, N. (2008). Compulsive hoarding: A qualitative investigation of partner and carer perspectives. British Journal of Clinical Psychology, 47, 59-73.

Worden, J. W. (2001). Grief counselling and grief therapy. New York, NY: Springer. Yalom, I. D., \& Lieberman, M. A. (1991). Bereavement and heightened existential awareness. Psychiatry, 54, 334-345. 
Angela Smith completed the Trent Clinical Psychology Doctorate course in 2010. She now works as a clinical psychologist in mental health services for older people. She has research interests in bereavement, particularly bereavement by suicide.

Stephen Joseph is a professor of psychology, health, and social care in the School of Sociology and Social Policy at the University of Nottingham, where he is co-director of the Centre for Trauma, Resilience and Growth. He is an honorary consultant psychologist in psychotherapy at the Nottinghamshire NHS Healthcare Trust. His research interests are in positive psychology, posttraumatic growth and psychotherapy.

Roshan das Nair is a consultant clinical psychologist with the Nottingham University Hospitals NHS Trust and a research tutor on the Trent Doctorate in Clinical Psychology. His research interests are in sex, sexuality, sexual health, and HIV/AIDS. 